\title{
DWELLING DENSITY VARIABILITY ACROSS GOVERNMENT-BUILT MULTIFAMILY APARTMENTS IN LAGOS
}

ADEBAYO, A. K. and *IWEKA, A.C.O.

http://dx.doi.org/10.4314/ejesm.v6i5.9

\section{Received 10th May 2013; accepted 15th August 2013}

\begin{abstract}
This study examined the variability of dwelling density across different classifications of multifamily apartments built by Lagos State Development and Property Corporation (LSDPC) in Lagos, Nigeria. Six design prototypes used to build several multifamily apartments in four estates were purposively selected as case study. The focus was on comparing how the interior spaces in the six multifamily prototype apartments were occupied during habitation. Overall population of apartments studied was 7,764 representing the total number of apartments in the four purposively selected estates. A sample of 7.5\% (582) was chosen using stratification and systematic random techniques. A survey research technique was adopted to obtain responses to pre-tested questionnaires regarding the demographic data of occupants. Data analysis was done by applying adult-equivalent number of occupants based on Canadian National Occupancy Standards (CNOS) and the Equivalized Crowding Index (ECI). The intensity of dwelling density during habitation across various apartment classifications was presented in two parts namely single measure and group measure. The results obtained using the group measure show that households containing three to five persons were the most dominant in all apartment types. The result also shows that there was no substantial disparity in dwelling density across different apartment classifications when analyzed using single measure approach. This finding was supported by the results of a chi-square test which found that, at 95\% confidence level, apartment type had no significant effect on dwelling density in LSDPC's multifamily apartments. The findings are important for policy issues that relate apartment types to household sizes and crowding. The results are also relevant for policies regarding provision of infrastructure and other complementary facilities in government-built estates to improve residents' welfare and quality of life.
\end{abstract}

Key words: dwelling density, home spaces, housing units, multifamily apartments

\section{Introduction}

In Lagos, Nigeria, the government has been involved over the years in the provision of residential units through the Lagos Executive Development Board (LEDB), now Lagos State Development and Property Corporation (LSDPC) (Fadahunsi, 1985; Ilesanmi, 2006; Iweka, 2012). Like what is obtained in many other countries, the housing units available in LSDPC's housing estates were designed and built without empirically determining who the tenants or owners will be.

In the early 1980s, new design models that essentially focused on multifamily apartments were adopted and used for housing estates at Amuwo Odofin, Iba, Iponri, Abule Nla, Ojokoro, Ipaja, Dolphin I, Dolphin II, Oko Awo, etc. In addition, high rental accommodation for medium income and upper medium income groups emerged in Victoria Island, Ikoyi, Surulere, Ebute-Metta, Ogba, and Alapere.

Department of Architecture, Faculty of Environment

Sciences, University of Lagos. Akoka-Yaba, Lagos, Nigeria

*Corresponding author: tonyiweka@yahoo.com
According to Mayaki (2009), the overall number of housing units produced by LSDPC to the year 1992 had grown to about 17,000 in several locations, with the adoption of new design models (Table 1).

Despite the fact that there is a variety of multifamily dwelling prototypes in LSDPC's housing estates, there is inadequate knowledge of how the different apartment classifications are occupied. This makes it difficult to identify the multifamily dwelling unit prototypes that are efficient in terms of density and better interior spatial qualities. This raises the need to address the question: how are the interior spaces in different classifications of LSDPC's multifamily apartments working? The number of persons to a dwelling, the household demographic characteristics, and the physical design of the habitable spaces in the dwelling units are all highly regarded when considering the quality of life of residents. 
Table1 LSDPC low and medium income estates containing multifamily housing units

\begin{tabular}{lll}
\hline S/N & Name of Estate & No of Units \\
\hline 1. & Abesan & 4,272 \\
2. & Amuwo-Odofin & 2,068 \\
3. & Anikantamo & 714 \\
4. & Dairy Farm/Ijaiye & 708 \\
5. & Dolphin II. & 576 \\
6. & Iba & 2,388 \\
7. & Iponri & 1,026 \\
8. & Isolo & 3,664 \\
9. & Ojokoro & 534 \\
10. & Ebute-Meta & 528 \\
11. & Femi Okunnu & 405 \\
12. & Ijaiye & 796 \\
Total & & 17,679 \\
\hline
\end{tabular}

Source: Iweka (2012)

\section{Aim and objectives}

The aim of this study was to examine the variability of dwelling density among different classifications of LSDPC's multifamily apartments in Lagos, Nigeria. The specific objectives are: (a) to determine the levels of occupancy in the various types of apartments; (b) to evaluate the effect of apartment type on dwelling density

Home spaces and habitable rooms in multifamily apartments: The interior spaces of the physical structure of LSDPC's apartments are the primary focus of this research. Each single interior space is typically referred to as a room. According to $\mathrm{Li}$ (2003), rooms can be classified into five categories of spaces, based on the functions and activities that take place in them. These are: (a) living (b) work and study (c) resting (d) service, and (e) circulation. Li further grouped living, work and study, and resting spaces as primary spaces, while service and circulation spaces are regarded as support spaces. All support spaces are outside the scope of the current study.

A number of scholars tend to agree that habitable rooms are spaces that normally serve the functions for sitting, sleeping, eating, studying or recreation (Li, 2003; Obateru, 2005). However there appears to be no convergence of opinions among earlier researchers regarding the definition of primary spaces. For example, while Li (2003) included kitchens as part of primary spaces for work, Obateru (2005) defined kitchens as habitable rooms. Again Li (2003) integrated bathrooms and closets into the primary spaces reserved for resting, whereas Obateru (2005) excluded the same spaces from being classified as habitable rooms. Asquith (2006) also classified kitchens as habitable rooms, arguing that apart from cooking and eating, a kitchen may also be used for many other purposes like working, homework, playing, entertaining, hobbies and talking. In the present study kitchens were regarded as habitable rooms, while bathrooms and closets were not regarded as habitable rooms.

\section{Study Area}

Lagos Metropolitan area is an African megacity which is located in south-western Nigeria on the West Coast of Africa and situated within latitudes $60^{\circ} 27^{\prime} 11^{\prime \prime} \mathrm{N}$ and Longitudes $3^{\circ}$ $23^{\prime} 45^{\prime \prime}$ E. Lagos metropolis constitutes the greater parts of the habitable portion of Lagos State. The state is bounded in the north and east by Ogun State, in the west by the Republic of Benin and the south by the Gulf of Guinea. It is $800 \mathrm{~km}$ southwest of Abuja, the Nigeria's capital and the smallest yet the most populated state in the country with an estimated population of 18.5 million inhabitants (Salau, 2010). Lagos State (2004) remarks that Lagos will be the third largest global city in the world by 2025 , with an estimated population of 24.0 million people.

Lagos State harbours $65 \%$ to $70 \%$ of the country's total industrial and commercial activities and also accounts for approximately $50 \%$ of the manufacturing concerns. The built-up area of Lagos metropolis has an average projected population density of about 20,000 people per square kilometre (Mabogunje, 2002). The high growth rate of Lagos has tremendous consequences, especially in the area of providing adequate housing for teeming urban population. Thus government's attention on housing provision is a prerequisite for Lagos to sustain its leadership in commercial and national development. 


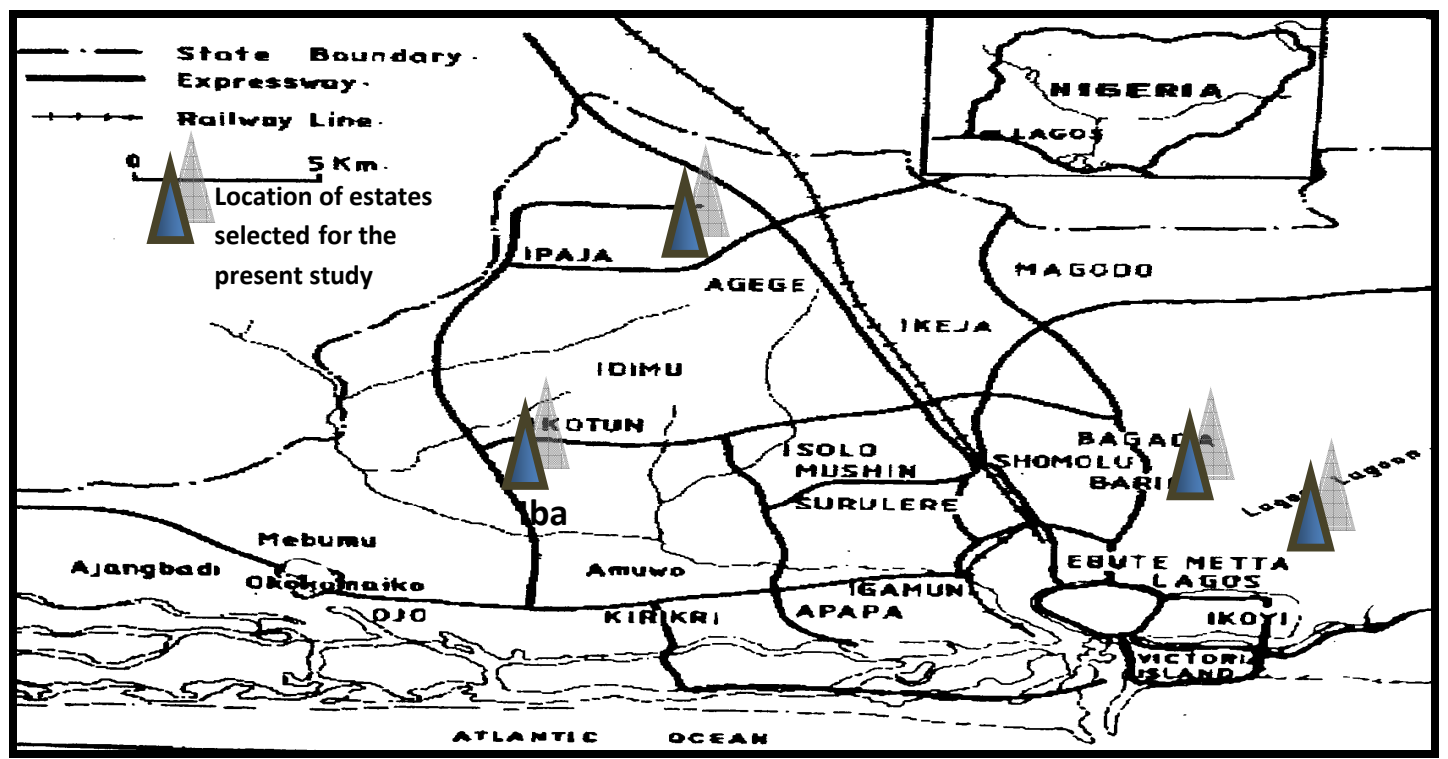

Figure1 Map of Lagos State, Nigeria

\section{Methodology}

The multifamily dwelling units found in LSDPC's housing estates were arranged according to whether they are two-bedroom type, three-bedroom type or four bedroom type. These classifications were further grouped according to variations in the spatial organization of the floor plans.

A case study methodology of LSDPC as an entity was adopted for this research. Six design prototypes that were used to build several multifamily apartments in four LSDPC's estates were purposively selected. The methodological issues involved were based on survey research design. The survey research component provided data about the number of persons per apartment, number of bedrooms and number of habitable rooms. The four estates selected were: (1) Abesan with 4,272 apartments, (2) Iba with 2,388 apartments (3) Dolphin II with 576 apartments, and Ebute-Metta with 528 apartments. The population for the study was 7,764 comprising two-bedroom, three-bedroom and four-bedroom multifamily apartments, also called housing units or dwelling units in this study. This represents the total number of apartments in the four selected estates.

Sampling techniques and size: the four estates purposively chosen for detailed study were stratified as follows:
Abesan low-income:
Dolphin low-income:
Iba low-income:
Ebute-Metta medium-income:

Two types
Two types
One type
Two types

The matching of location with apartment category was used to obtain the grouping of apartments into Type 1 (2-bedroom) at Abesan, Type 2 (2-bedroom) at Dolphin, Type 3 (3bedroom) at Abesan, Type 4 (3-bedroom) at Iba, Type 5 (3-bedroom) Dolphin and Type 6 (4bedroom) at Ebute-Metta; for purposes of analyses. In all, a $7.5 \%$ sample of the housing units was chosen for this study, amounting to 582 units. Stratification and systematic random sampling techniques were applied to select unit design types available in each estate to ensure that all population proportions were matched in

\section{(a) 2-bedroom \\ (b) 3-bedroom \\ - (a) 2-bedroom \\ (b) 3-bedroom \\ - 3-bedroom \\ 4-bedroom}

the sample. The measure of dwelling density was decomposed from responses to pre-tested questionnaire items pertaining to the number of persons in the housing unit. Furthermore, the questionnaire instrument was used to obtain information that revealed other demographic data of occupants such as age, sex, and marital status.

Procedure for data analysis: This study utilized two internationally recognized indexes to compute what constitutes an adult-equivalent person. These are the Canadian National Occupancy Standard (CNOS) and the Equivalized Crowding Index (ECI). Thus each individual who is in a marital relationship is 
rated as one-half. Children under one year are disregarded. Children one year of age or over, but less than eighteen years of age are counted as one-half. Household members aged eighteen years or over are counted as one. The outcome gives an equivalized number of people living in an apartment (Morrison, 1994; Basavarajappa, 1996; Schuluter et al., 2007; Australian Bureau of Statistics Year Book, 2008; Seeling et al., 2008; Iweka et al., 2009; Iweka, 2012).

In this study, dwelling density is interpreted as the way the multifamily apartments were actually occupied during usage. It provides useful data for comparison across various design types. The dwelling density for each existing LSDPC's multifamily apartment type was computed in this research for adult equivalent occupants. Comparisons such as these are capable of providing information about strength of relationships.

The architectural drawings purchased from LSDPC were used to extract the initial interior design of six apartment prototypes covered in this research. To ensure consistency, data collected from the architectural drawings were cross-checked with data obtained through direct measurement and participant observation of the housing units during the field work.

The total effective return rate of the questionnaire was 32\% (184). Eight out of all returned questionnaires were defective, hence could not be used in the data. Therefore the actual number of questionnaires analyzed was 176.

\section{Result and Discussion}

The dwelling density for each of the six apartment types investigated in this study was determined based on the number of adultequivalent occupants per apartment. The observed dwelling density during habitation across various design models is presented in two parts viz: single measure and group measure.

\section{Single Measure:}

Table 2 shows the mean value of actual dwelling density extracted from the responses to the questionnaires for the different design models. The dwelling density for each of the six design models investigated in this study was determined, based on the number of adultequivalent occupants per apartment.

Generally, the results show that there was no substantial disparity in the incidence of dwelling density across design types when assessed on the basis of adult-equivalent number of persons per apartment. However, it could be observed that the two design models at Dolphin II recorded the highest dwelling density. The Type 2 (twobedroom) design model can therefore be regarded as facing the highest level of crowding stress.

The bedroom and habitable room indicators show similar trend. The average dwelling density trend was less than two persons per bedroom and less than one person per habitable room. These figures fall within acceptable levels of crowding, based on CNOS and ECI indices.

Table 2 Single measure of dwelling density

\begin{tabular}{lccccc}
\hline & $\begin{array}{l}\text { Number of } \\
\text { bedrooms }\end{array}$ & $\begin{array}{l}\text { Number of } \\
\text { habitable } \\
\text { rooms }\end{array}$ & $\begin{array}{l}\text { Adult-equivalent } \\
\text { occupants per } \\
\text { apartment }\end{array}$ & $\begin{array}{l}\text { Adult-equivalent } \\
\text { occupants per } \\
\text { bedroom }\end{array}$ & $\begin{array}{l}\text { Adult-equivalent } \\
\text { occupants per } \\
\text { habitable room }\end{array}$ \\
\hline $\begin{array}{l}\text { Type 1 (2-bedroom) at } \\
\text { Abesan } \\
\text { Type 2 (2-bedroom) at }\end{array}$ & 2 & 4 & 3.31 & 1.66 & 0.83 \\
$\begin{array}{l}\text { Dolphin } \\
\text { Type 3 (3-bedroom) at } \\
\text { Abesan } \\
\begin{array}{l}\text { Iype 4 (3-bedroom) at } \\
\text { Iba }\end{array}\end{array}$ & 3 & 4 & 4.17 & 2.09 & 1.04 \\
$\begin{array}{l}\text { Type 5 (3-bedroom) } \\
\text { Dolphin } \\
\text { Type 6 (4-bedroom) at }\end{array}$ & 3 & 5 & 3.36 & 1.12 & 0.67 \\
Ebute-Metta & 4 & 5 & 3.77 & 1.38 & 0.75 \\
\hline
\end{tabular}




\section{Group Measure:}

The variability of dwelling density among the six design models investigated in this study was equally considered by grouping all the occupants into three categories. These are: (i) households that harboured one to two adultequivalent occupants, (ii) households that harboured three to five adult-equivalent occupants, and (iii) households that harboured six or more adult-equivalent occupants (Table 3 ).

The groupings were indicative of the intensity of dwelling density in each apartment type during habitation. The groupings were used as a basis for understanding and interpreting the variations in the dwelling density across various design models of LSDPC's multifamily apartments during habitation. This was the focus of the present research.

Table 3 shows that households containing three to five persons were the most dominant in all apartment types. Type 1 (two-bedroom) at Abesan ranked highest with $77.8 \%$ (14) respondents belonging to this group, while Type 3 (three-bedroom) at Iba ranked least with 53.3\% (8). The results for the other apartment types were Type 2 (two-bedroom) at Dolphin, 66\% (10); Type 3 (three-bedroom) at Abesan 66.2\% (45); Type 5 (three-bedroom) at Dolphin, 68.0\% (17); and Type 6 (four-bedroom) at Ebute-Metta, $65.7 \%$ (23).

Table 3 Group measure of dwelling density

\begin{tabular}{llll}
\hline Apartment & $1-2$ & Number of occupants during habitation \\
& $3-5$ & 6 and above \\
\hline Type 1 (2-bedroom) at Abesan & $3(16.6 \%)$ & $14(77.8 \%)$ & $1(5.5 \%)$ \\
Type 2 (2-bedroom) at Dolphin & $1(6.7 \%)$ & $10(66.7 \%)$ & $4(26.7 \%)$ \\
Type 3 (3-bedroom) at Abesan & $17(25.0 \%)$ & $45(66.2 \%)$ & $6(8.8 \%)$ \\
Type 4 (3-bedroom) at Iba & $4(26.7 \%)$ & $8(53.3 \%)$ & $3(20.0 \%)$ \\
Type 5 (3-bedroom) Dolphin & $3(12.0 \%)$ & $17(68.0 \%)$ & $5(20.0 \%)$ \\
Type 6 (4-bedroom) at Ebute- & $9(25.7 \%)$ & $23(65.7 \%)$ & $3(8.6 \%)$ \\
Metta & & & \\
Type 1 (2-bedroom) at Abesan & $3721.0 \%)$ & $117(66.5 \%)$ & $22(12.5 \%)$ \\
\hline
\end{tabular}

Table 3 further illustrates that households comprising one to two persons constitute the second most dominant in apartment Type 1 (twobedroom) at Abesan (17\%), Type 3 (threebedroom) at Abesan (25\%), Type 4 (threebedroom) at $\mathrm{Iba}(27 \%)$, Type 6 (four-bedroom) at Ebute-Metta (26\%). Among these four design models, households that contain six or more persons were very few.

Household size of six or more adultequivalent persons was the second most dominant in only two design models. These are Type 2 (two-bedroom) at Dolphin II (27\%), and Type \% (three-bedroom) at Dolphin II $(20 \%)$. These two design models incidentally, were located in Dolphin II housing estate. Apartments that harbour one to two persons were the least occurring in the two types. Generally, the result shows that there was no substantial disparity in the incidence of dwelling density among various households occupying different apartment types. This finding was supported by the results of a chi-square test employed to evaluate the effect of apartment type on dwelling density. The result gave a chi-square figure of 10.525 and a p-value of 0.396 . Thus this study found that, at $95 \%$ confidence level, design model (apartment type) had no significant effect on dwelling density.

\section{Conclusion}

The average dwelling density trend using bedroom and habitable room indicators fall within acceptable levels of crowding based on CNOS and ECI indexes. The results show no substantial disparity in the incidence of dwelling density across design types when assessed on the basis of adult-equivalent number of persons per apartment. The results further show that households containing three to five persons were the most dominant in all apartment types. These findings were supported by the results of a chisquare test which found that, at $95 \%$ confidence level, apartment type had no significant effect on dwelling density in LSDPC's estates.

The findings from this study regarding dominant household size is consistent with claims by Asiyanbola (2010) that the average household size in Nigeria was 4.48, based on an analysis of Nigerian Population Commission household survey, 1996/1996. On the other hand, a comparison between the results of this research and Algeria's national average household size of 7.55 in 1988, based on Sibley-Behloul (2005)'s 
study reveals a substantial disparity between Nigeria and Algeria.

These findings are important for policy issues that relate apartment types to household sizes and crowding. The results are also relevant for policies regarding provision of infrastructure and other complementary facilities in government-built estates to improve residents' welfare and quality of life.

\section{References}

Alade, W. (2010), Trip Length Characteristics in Lagos Metropolis. Proceedings of the National Conference on Emerging Global City: The African Challenge, Department of Urban and Regional Planning, University of Lagos. 384 394

Asiyanbola, A. R. (2010), Urban household crowding, psychological well being and gender in developing countries: Nigeria. Paper presented at the Population Association of America Meeting held in Dallas, Texas, USA.

Asquith, L. (2006), Evaluating and illustrating domestic space use: Collecting and analyzing behavioural data for space syntax analysis. Retrieved March 8, 2008 from www.space.bartlett.ucl.ac/events/sc06/proceedin gs/asquith.sssc.pdf.

Australian Bureau of Statistics (2008), Housing utilization. Year Book Australia, 2008.

Basavarajappa, K. G. (1998), Living arrangements and residential overcrowding: The situation of older immigrants in Canada 1991. The Analytical Studies Branch Research paper Series No. 115, Statistics Canada, September.

Fadahunsi, S. O. (1985), Fifty years of housing in Nigeria. In P. Onibokun (Ed.), Housing in Nigeria (pp. 105 -132). NISER, Ibadan. (Unpublished doctoral dissertation). University of Birmingham.

Illesanmi, A.O. (2005), An evaluation of selected public housing schemes of Lagos State Development and Property Corporation, Lagos, Nigeria (Unpublished doctoral dissertation). Obafemi Awolowo University, Ile-Ife.

Iweka, A. C. O. (2012), A post-occupancy evaluation of dwelling density in multifamily apartments in public housing estates in Lagos (Unpublished doctoral dissertation). University of Lagos.

Iweka, A. C. O., Adebayo, A. K. and Igwe, J. M. (2009, June), Millennium development goals and slum alleviation in developing nations: The challenge of sufficient living area for households. Paper presented at the International
Conference on Millennium Development Goals and the Built Environment, Obafemi Awolowo University, Ile-Ife.

Lagos State (2004), Perspectives on Lagos Economy Lagos State Ministry of Economic

Planning and Budget. Ikeja, Lagos.

Li, Y. (2003), The integration of technology into home space in the 2020s (Unpublished masters thesis). Virginia Commonwealth University.

Mabogunje, A.L. (2002), Re-Constructing the Nigerian city: The new policy of urban development and housing. In D. Amole, A. Ajayi, \& A. Okewole, (Eds.), The city in Nigeria: Perspectives, issues, challenges, strategies. Obafemi Awolowo University, IleIfe, Nigeria.

Mayaki, S. S (2009), Effective housing delivery in a megacity development. Paper presented at The Nigeria Institution of Estate Surveyors and Valuers (Lagos Branch) Conference on "Megacity development in a developing eonomy", Lagos.

Morrison, P.S. (1994), Housing occupancy and the changing size of households and dwellings in New Zealand 1951 - 1991. New Zealand Population Review, 20(1 \& 2), 32-64.

Obateru, O. (2005), Controlling residential densities. (2nd ed.). Ibadan: Penthouse Publications (Nig).

Salau, T. I. (2010), Traffic Impact Analysis as a Tool for Planning Permit Consideration in Lagos State: Guidelines and Procedures. Proceedings of the National Conference on Emerging Global City: The African Challenge, Department of Urban and Regional Planning, University of Lagos. 299 - 307

Schluter, P., Carter, S. and Kokaua, J. (2007), Indices and perception of crowding in pacific households domicile within Auckland New Zealand: Findings from the pacific islands families study. The New Zealand Medical Journal, 120(1248), 1-12.

Seeling, T., Milligan, V., Phibbs, P. and Thompson, A. (2008), Reconceptualizing housing need in the context of the 21st century Australian housing policy. Retrieved October 10, 2010, from Australian Housing and Urban Research Institute Positioning paper (110) Web site: http://www.ahuri.edu.au/research_agenda_ funding/ research_agenda/archived_research_agendas

Sibley-Behloul, M. (2005), Informal transformations of formal housing estates in Algiers and Cairo. In T. Shakur (Ed.), Cities in transition: Transforming the global built environment (pp. 88-98). Liverpool: Open House Press. 